\title{
A docência no contexto hospitalar: uma prática possível e necessária
}

Andreia Straube Araujo', Gilmar de Carvalho Cruz²

\begin{abstract}
Resumo
O presente texto advém de pesquisas realizadas em uma instituição de saúde localizada na cidade de União da Vitória, no Paraná, e tem como objetivo verificar como se configura a prática pedagógica dos docentes que atuam em classes hospitalares. A metodologia adotada foram observações e entrevistas com questões semiestruturadas para os/as professores/as. Atualmente, o professor tem um universo de múltiplas possibilidades de atuação, como presídios, assentamentos, comunidades indígenas e quilombolas, empresas, sindicatos, programas televisivos, abrigos, entre tantos outros territórios educativos, dentre eles os hospitais. Essa diversidade de contextos educacionais tem mostrado que ensinar e aprender já não são mais ações restritas às escolas e que o papel do professor tem recebido outras nuances e se ampliado, assim como os campos para sua atuação. O professor já não é apenas um mediador do conhecimento, ele atende a diversas necessidades e passa a dar visibilidade a funções necessárias e que, até pouco tempo atrás, eram desconhecidas pela população e pelos próprios atores desse cenário tão brilhante que é a educação. A educação é direito de todos e dever do Estado e da família. O direito à educação se expressa como direito à aprendizagem e à escolarização, e toda criança e adolescente têm esse direito garantido, independente do período que irá passar no hospital. A classe hospitalar, além de garantir o direito ao acesso, à manutenção e à continuidade da escolarização, possibilita a redução dos riscos de fracasso escolar ou de evasão do sistema educacional na pós-hospitalização e o papel do docente neste contexto é primordial.
\end{abstract}

\section{Palavras-chave}

Classe Hospitalar. Prática Pedagógica. Inclusão Social.

1. Mestre em Educação pela Universidade do Centro-Oeste do Paraná, pedagoga na rede estadual de educação do Paraná e psicóloga. E-mail: andreiastraubearaujo@hotmail.com.

2. Pós-doutor em Educação pela Universidade do Estado do Rio de Janeiro, professor associado da Universidade Estadual do Centro-Oeste, professor permanente do Programa de Pós-Graduação em Educação da Universidade Estadual de Ponta Grossa, líder do grupo de pesquisa "Formação Profissional em Contextos Educacionais Inclusivos" (FOCUS). E-mail: gilmailcruz@gmail.com. 


\title{
Teaching in hospitals: a possible and necessary practice
}

\author{
Andreia Straube Araujo*, Gilmar de Carvalho Cruz ${ }^{* *}$
}

\begin{abstract}
This paper is a research conducted in a health institution at União da Vitória, Paraná state. It aims to observe the pedagogical practice of teachers who work on a hospital class. The method used is observations and interviews with semi-structured questions for teachers. Nowadays, teachers can act on prisons, settlements, indigenous and quilombola communities, businesses, unions, television programs, shelters, among many other educational areas, including hospitals. These different educational contexts have shown that teaching and learning are no longer restricted to schools and that the role of the teacher has been expanded to other nuances as well as fields. He is no longer just a mediator of knowledge, but satisfies different needs and gives the necessary visibility to functions that until recently were unknown to people and to the actors of the bright scenario education can be. Education is everyone's right and an obligation of the state and the family. It is expressed as a right to learning and schooling and every child and teen must have it in any period they will spend in the hospital. Hospital education in addition to guarantee the right to access, maintenance and continuity of schooling, enables the reduction of risk of school failure or dropout in post-hospitalization. The role of the teacher is crucial in this context.
\end{abstract}

\section{Keywords}

Hospital Education. Teaching Practice. Social Inclusion.

\footnotetext{
* MSc in Education, State University of Center-West of Paraná, State of Paraná, Brazil; pedagogue, state education system, Paraná, Brazil; psychologist. E-mail: andreiastraubearaujo@hotmail.com.

** Post-Doctorate in Education, Rio de Janeiro State University, State of Rio de Janeiro, Brazil; professor, CenterWest State University, State of Paraná, Brazil; professor, Post-Graduation Program in Education, Ponta Grossa State University, State of Paraná, Brazil; leader of the research group "Professional Education in Inclusive Educational Contexts" (FOCUS). E-mail: gilmailcruz@gmail.com.
} 


\section{Introdução}

A cada dia, aumenta a necessidade de uma educação inclusiva, flexível e heterogênea, que possibilite uma articulação entre a universalidade e o pluralismo do público atendido. Faz-se necessário repensar uma educação diferenciada e atuante em diversos contextos, que seja capaz de proporcionar atendimento educacional a uma gama de diversidade, pois a arte de educar não ocorre somente na escola e entre alunos iguais, até mesmo porque a homogeneidade é uma utopia na área educacional, visto que se atende a diversos alunos, cada um com uma história de vida, valores, cultura e pensamentos diferentes.

A classe hospitalar garante à criança, ao adolescente e ao jovem a continuação do processo de educação escolarizada e estimula a sua permanência após a alta. Essa atitude minimiza o risco de um possível fracasso escolar gerado pelo excesso de faltas, o que pode ocasionar perdas significativas para a vida acadêmica dos sujeitos e, até mesmo, dificultar a recuperação de sua saúde. Ela é, ainda, um auxílio significativo na redução do tempo de internação e do estresse causado pela doença, pelo local onde está inserido e pelo tratamento recebido, além de manter o vínculo do paciente com o mundo externo, atendendo às suas necessidades intelectuais.

A ação pedagógica deverá apresentar uma multiplicidade de práticas com o intuito de criar tentativas de contribuição a esses alunos para auxiliá-los a enfrentar os obstáculos causados pela doença e para que, apesar de toda dor, sofrimento e medo, eles sejam capazes de descobrir, redescobrir e recriar seus desejos e expectativas de vida. Tanto as práticas pedagógicas como o perfil profissional do docente dentro do hospital devem ser diferenciadas, porque o espaço também é diferenciado.

A formação do professor para a classe hospitalar não deve se pautar apenas em questões didáticas. O docente precisa conhecer as patologias mais frequentes no hospital, principalmente aquelas que acometem seus alunos, ter noções terapêuticas que fazem parte da rotina na enfermaria, as formas de tratamento, medicação usada e sua influência no indivíduo. Além disso, deve conhecer as condições de saúde de seus alunos, suas potencialidades e possibilidades e colaborar para que os alunos-pacientes compreendam a hospitalização. O docente deve ouvir as histórias de vida dos alunos, para poder compreendê-los melhor e ajudá-los a superar e ressignificar sua internação e sua doença.

De acordo com Freire (1998, p. 135), escutar é obviamente algo que vai mais além da possibilidade auditiva de cada um. Escutar, no sentido aqui discutido, significa a disponibilidade permanente por parte do sujeito que escuta para a abertura à fala do outro, ao gesto do outro, às diferenças do outro.

Os professores das classes hospitalares trabalham com as dores e as incertezas de crianças e adolescentes hospitalizados e de suas famílias, ultrapassando fronteiras e levando alegria, fazendo com que esses alunospacientes valorizem o eu e a vida, apesar de toda subjetividade do universo hospitalar.

O termo "classes hospitalares" foi inserido pela Política Nacional de Educação Especial, que o define como "ambiente hospitalar que possibilita o atendimento educacional de crianças e jovens internados que necessitam de educação especial e que estejam em tratamento hospitalar". (BRASIL, 1994, p. 20). As classes hospitalares foram criadas com o seguinte objetivo:

Cumpre às classes hospitalares e ao atendimento pedagógico-domiciliar elaborar estratégias e orientações para possibilitar o acompanhamento pedagógico-educacional do processo de desenvolvimento e construção 
do conhecimento de crianças, jovens e adultos, matriculados ou não nos sistemas de ensino regular, no âmbito da educação básica e que se encontram impossibilitados de frequentar a escola, temporária ou permanentemente e, garantir a manutenção do vínculo com as escolas por meio de um currículo flexibilizado e/ou adaptado, favorecendo seu ingresso, retorno ou adequada integração ao seu grupo escolar correspondente, como parte do direito de atenção integral. (BRASIL, 2002, p. 13).

Autores como Ortiz e Freitas (2005) e Fonseca (1999) afirmam que a primeira classe hospitalar no Brasil surgiu em 1950, no Hospital Jesus, no Rio de Janeiro. Nessa época, segundo registros, oitenta crianças em idade escolar se encontravam em atendimento (RITTMEYER, 2000). Entretanto, a classe hospitalar só foi reconhecida pelo Ministério da Educação em 1994, como resultado de políticas públicas, estudos acadêmicos realizados a partir de observações e com o intuito de respeitar as necessidades de crianças e jovens internos em instituições de saúde.

Não há como negar que a assistência educacional no hospital é de suma importância e de relevância social, pois, por meio desse serviço, assegura-se o direito à educação de diversas crianças e adolescentes que vivenciam o adoecimento e têm seu processo de escolarização interrompido. Por meio das classes hospitalares, pode-se obter significativa redução do fracasso escolar e também dar um novo significado ao hospital, que se coloca, muitas vezes, como um ambiente de sofrimento e angústia.

Em sua prática pedagógico-educacional diária, as classes hospitalares visam dar continuidade ao ensino dos conteúdos da escola de origem da criança ou adolescente, e/ou operam com conteúdos programáticos próprios à faixa etária das crianças e jovens hospitalizados, o que os leva a sanar dificuldades de aprendizagem e/ou a oportunidade de aquisição de novos conteúdos intelectivos. (FONSECA, 1999, p. 13).
Aclasse hospitalar, além de obter resultados positivos quanto aos esforços que despendem na área educacional, confirma-se como um lócus necessário à mediação entre o hospital e a escola, no intuito de propiciar novas significações ao processo de adoecimento e hospitalização, criar aproximação de saberes interdisciplinares e manter uma relação socioafetiva entre os atores da educação na instituição de saúde.

O hospital tem se configurado como um ambiente propício à assistência educacional. Embora pareça um local improvável e inusitado para o processo de ensino-aprendizagem, ele tem se mostrado um campo fértil e cheio de possibilidades para que a educação aconteça. A experiência e as pesquisas nessa área têm mostrado que é possível fazer uma educação de qualidade e que o ambiente hospitalar fornece uma gama de oportunidades e possibilidades de enriquecimento para o processo de ensino e aprendizagem. O local que antes era exclusivo da saúde, agora passa a dividir espaço com outras áreas e outros profissionais, para proporcionar um atendimento mais humanizado aos pacientes. Dentre as ações realizadas para tornar a hospitalização menos traumática estão as classes hospitalares.

O hospital é um mundo asséptico, desconhecido e bastante impessoal, onde o enfermo, seja criança ou adulto, perde sua identidade e passa a ser um número de leito. O paciente, sobretudo a criança, sente como se estivesse vivenciando uma inclusão compulsória em um mundo desconhecido, que Ihe provoca diferentes sensações e sentimentos, como medo, angústia e oscilações psíquicas, que variam desde a fragilidade ao abandono, causando, como consequência, a alteração do estado de saúde do paciente. A hospitalização, seja ela temporária ou permanente, levanta a necessidade de assistência educacional, para que também se viabilizem os conceitos de integração e normalização, além de proporcionar a continuidade nos estudos e diminuir casos de 
evasão e reprovação em crianças, adolescentes e jovens acometidos por problemas de saúde.

A hospitalização não pode ser exclusão. Assim como todos têm direito garantido por lei a receber uma educação gratuita e de qualidade, a criança ou o adolescente que se encontra em tratamento de saúde também possui o direito de ser assistido no âmbito educacional e participar das atividades com outros pares, através do currículo comum, conforme suas necessidades e possibilidades. A educação deve proporcionar uma aprendizagem significativa, que respeite as características e as necessidades individuais de cada aluno e forneça subsídios para que ele possa se desenvolver plenamente como pessoa, além de assegurar a igualdade de oportunidades.

A escola não se configura apenas como um local de transmissão de conhecimentos e socialização, mas também como um espaço para a construção da identidade. Partindo desse princípio, é preciso salientar a importância de se assegurar a individualidade, a liberdade e a autonomia de cada sujeito.

O processo de ensino pode ocorrer em diversos contextos e situações, mas é inevitável o surgimento da imagem da escola em nossa mente quandofalamosem educação. Otermoeducação está atrelado a criações histórico-culturais de cada povo. Segundo Brandão (2007, p. 10),

educação é, como outras, uma fração do modo de vida dos grupos sociais que a criam e recriam entre tantas outras invenções de sua cultura, em sua sociedade.

De acordo com Paula (2004, p. 25), a educação

não está mais circunscrita aos muros da escola. Ela acontece através da mídia, em diferentes locais como hospitais, presídios, na rua. Há de se considerar que, quando os educadores começam a sair dos muros da escola e frequentar ambientes diversificados, a educação assume características bem peculiares, que se diferem um pouco das instituições formais, mas conservam elementos comuns. É necessário lembrar que essa forma de educar tem compromissos significativos com a formação de quem se educa e quem é educado.

A educação no ambiente hospitalar resgata a importância do exercício da humanização, com a qual se assume uma postura de respeito e acolhimento ao outro nos ambientes hospitalares e não apenas à atenção a saúde.

A classe hospitalar constitui uma necessidade não só para o paciente, mas para todos os envolvidos no tratamento - família e profissionais do hospital tanto da área da saúde como da educação - e ela não deve apenas se basear na assistência educacional, mas, sim, proporcionar assistência psicológica, emocional e buscar a promoção da qualidade de vida. É o desejo de proporcionar à criança enferma a manutenção escolar de qualidade, que deve impulsionar a existência da aliança hospitalfamília-escola.

Segundo Menezes (2010 apud PARANÁ, 2010, p. 25),

Oferecer atendimento escolar aos alunos em situação de internamento permite-lhes a manutenção do vínculo com os colegas e professores da escola de origem, pois eles não se sentirão alheios ao sistema de educação formal, podendo continuar como elementos integrantes, com acesso ao conhecimento e em igualdade de condições. Vale ressaltar que a continuidade do processo de escolarização do aluno internado é um fator que assegura seu desenvolvimento intelectual, embora não existam dados para a comparação entre alunos atendidos e o dos não atendidos pela Classe Hospitalar. É fato percebido pela equipe de saúde que existe uma diminuição do tempo médio de permanência desses pacientes alunos no hospital e dos índices de abandono ao tratamento, como também é possível notar que a recuperação dos pacientes atendidos pelo Serviço é mais rápida. 
A hospitalização pode ser vivenciada de forma dolorosa pelo paciente, pois esse processo envolve mudança de rotinas, alteração das atividades realizadas diariamente, separação de amigos, familiares, objetos e locais que Ihe são significativos para sujeitar-se a um tratamento por vezes doloroso, invasivo e angustiante. A criança ou o adolescente passa a encarar situações e sentimentos não vivenciados anteriormente. Toda essa situação gerada pela mudança repentina pode levar o paciente a sofrer interferências em seu desenvolvimento social, afetivo e intelectual, o que pode possibilitar um fracasso escolar e psicológico.

Munhóz e Ortiz (2006, p. 67) apontam as mudanças que podem ocorrer com a hospitalização: a primeira "refere-se à desestruturação do sistema biopsicossocial", seguida pela "interrupção do processo de desenvolvimento intelectual, afetivo e da personalidade". Na classe hospitalar, o pacientealuno tem a possibilidade de acelerar sua recuperação, pela redução da ansiedade e do medo advindos do processo de adoecimento. Nesse contexto, o papel do professor é fundamental. Ele passa a ser um vínculo entre a realidade do hospital e a escola de origem do aluno-paciente, sendo a mediação pedagógica um meio para a realização de ressignificações da nova rotina vivenciada pelo educando, auxiliando-o no entendimento dos procedimentos médicos e no acompanhamento pedagógico.

Fontes (2009, p. 201), ao comentar sobre o professor da classe hospitalar, afirma que:

é um trabalho especializado bastante amplo que não se reduz à escolarização da criança hospitalizada. Ela busca levar a criança a compreender seu cotidiano hospitalar, de forma que esse conhecimento Ihe traga um certo conforto emocional. Isso lhe pode ajudar a interagir com o meio de uma forma mais participativa. [...] Ele é um professor diferente daquele da sala de aula, porque não está na escola, não está trabalhando com crianças "saudáveis", que podem fazer tudo a qualquer tempo. Enfim, é isto, do ponto de vista educacional, social e humano, o que denominamos, pesquisamos e acreditamos ser o papel da Pedagogia Hospitalar.

O hospital deve ser visto como um lugar de múltiplas aprendizagens, onde se faz necessário que o paciente, sobretudo a criança e o adolescente, entenda e saiba o que está acontecendo, o porquê de sua hospitalização, dos procedimentos invasivos a que será submetido e da rotina hospitalar, que é diferenciada da rotina de sua vida cotidiana. Nesse processo, o papel dos profissionais é essencial para ajudar o paciente a reduzir seu sofrimento e criar estratégias de enfrentamento dessa nova situação. Além dos aspectos técnicos, a formação docente e o exercício da educação em contextos inclusivos requer um olhar atento dos professores quanto às necessidades dos alunos ali inseridos. É preciso que eles e os pedagogos desenvolvam uma escuta sensível ${ }^{3}$ a partir das histórias de vida dos sujeitos, para que sejam capazes de entender e compreender as construções psicológicas, emocionais e comportamentais realizadas pelo aluno-paciente e por sua família no dia a dia do hospital e do adoecimento.

Por meio do diálogo e da escuta, o aluno-paciente pode resgatar sua autoestima, muitas vezes perdida com o aparecimento da enfermidade. Ele poderá refletir sobre a situação que enfrenta no momento, sendo capaz de ressignificar seu eu, sua doença e suas relações com a nova vida que se apresenta. O professor também será capaz de acolher as ansiedades

3. O termo "escuta sensível" aqui utilizado tem como referência as ideias de Barbier (2007, p. 94), para quem "a escuta sensível apoia-se na empatia [...] saber sentir o universo afetivo, imaginário e cognitivo do outro para 'compreender do interior' as atitudes e os comportamentos, o sistema de ideias, de valores, de símbolos e de mitos.." 
e dúvidas de seus alunos, possibilitando a construção de novos conhecimentos para buscar a melhora de seu quadro clínico. Menezes (2010 apud PARANÁ, 2010) contribui com suas observações ao afirmar que o professor da classe hospitalar não traz para dentro do hospital a escola formal, mas possibilita um espaço diferente para o processo de ensino, em que se respeita o tempo de ensinar e de aprender, contribuindo com a instituição de assistência à saúde e com o desenvolvimento dos educandos, sobretudo no que se refere à socialização e ao fortalecimento de laços que podem se romper devido à hospitalização, que afasta as crianças, os adolescentes e os jovens do seu dia a dia na escola. As práticas realizadas têm mostrado que os profissionais da educação que atuam nos hospitais são valorizados tanto pelos alunos e pais quanto por toda a equipe multiprofissional da área da saúde.

Se a educação inclusiva traz um novo paradigma de educação, é imprescindível que a formação dos professores também seja direcionada nessa perspectiva. É necessário que o profissional tenha contato e seja sensibilizado a respeito dessa nova maneira de se pensar as diferenças, para que se possa ter uma prática inclusiva. O professor não pode esquecer que seu aluno hospitalizado precisa de cuidados quanto a sua saúde física e mental, além de intervenções específicas. É importante que o professor da classe hospitalar tenha consciência de seu papel de mediador das práticas educativas dentro do hospital, uma vez que ele atua em conjunto com a equipe de saúde, atendendo não só o alunopaciente, mas também a família desse aluno.

O professor deve entender que a hospitalização é um processo que pode ser traumático para o aluno e ele é um instrumento essencial para auxiliar o educando a superar esse momento. Durante a internação, muitos "monstros" podem ser gerados na mente do paciente, sobretudo se ele for criança, em decorrência do desconhecido, do medo, das incertezas e por não saber o que vai ocorrer no hospital. O professor precisa ter consciência disso para realizar seu trabalho, necessita desenvolver a sensibilidade para ouvir, entender e compartilhar com os alunos e seus familiares toda carga de sentimentos, que inclui dor, medos, angústias e limitações que eles carregam durante o tratamento. De acordo com Matos (1998, p. 12),

A pedagogia hospitalar demanda necessidades de profissionais que tenham uma abordagem progressista, com uma visão sistêmica da realidade do escolar doente. Seu papel principal não será de resgate a escolaridade, mas de transformar essas duas realidades fazendo fluir sistemas que as aproxime e as integre.

A escola no hospital apresenta características muito peculiares. Nesse contexto, vive-se cotidianamente com a morte, a dor e os imprevistos. O professor nesse ambiente deve estar preparado para lidar com tudo isso e com as frustrações que poderão surgir. No entanto, não há nenhum curso, nenhuma graduação ou manual que ensine essa habilidade tão necessária para o cotidiano do hospital.

Nem todos os profissionais da educação têm perfil para trabalhar no hospital e alguns terminam por desistir da tarefa, situação decorrente também da falta de um treinamento consistente que prepare os profissionais para atuarem no contexto hospitalar; proporcione conhecimento das especificidades que ele encontrará ao ingressar no hospital; esclareça a rotina que será vivenciada, a dinâmica de funcionamento e outros fatores significativos para a atuação docente. Além de um treinamento inicial, também é necessário capacitação contínua, pois o hospital é um ambiente inusitado e heterodoxo, que recebe pacientes diferentes a cada dia e traz mudanças no trabalho dos professores. O professor, quando apresenta um perfil 
adequado e está preparado para os desafios que enfrentará, torna-se capaz de contribuir com a recuperação do aluno enfermo, dandoIhe carinho, afeto, atenção e valorização, conteúdos fundamentais para a saúde física, mental, psicológica, espiritual e cognitiva de qualquer indivíduo, principalmente de crianças e adolescentes que estão formando sua personalidade. Ao receber toda essa atenção necessária, o educando deixa de ter a doença como foco e consegue se envolver nas atividades estudantis, de forma mais produtiva, criativa e feliz, criando até mesmo expectativas para o futuro que, por vezes, são deixadas de lado, por medo ou desesperança.

O trabalho pedagógico no hospital é um desafio diário a ser alcançado e, para realizálo, não há receita pronta. A união entre pais e professores também é de fundamental importância para o trabalho, pois a família atua como apoio e cooperação para a qualidade do processo de ensino-aprendizagem e no restabelecimento da saúde da criança e do adolescente.

A realidade hospitalar é muito complexa, detentora de uma série de peculiaridades e ainda pouco conhecida e explorada, razão pela qual atuar como docente nas instituições hospitalares não é tarefa fácil. "O papel da educação é, assim, o de estimular esta aprendizagem que impulsiona o desenvolvimento humano, tornando o ambiente hospitalar menos hostil" (VASCONCELLOS, 2005, p. 301).

O saber é uma ferramenta que deve fazer parte da ação docente. Tardif (2007) afirma que os saberes docentes devem ser compreendidos a partir das condições estruturais de seu trabalho e que eles dependem das condições sociais, organizacionais, humanas e históricas vivenciadas pelos docentes.

O saber não é uma substância ou um conteúdo fechado em si mesmo; ele se manifesta através de relações complexas entre o professor e seus alunos. Por conseguinte, é preciso inscrever no próprio cerne do saber dos professores a relação com o outro, e, principalmente, com esse outro coletivo representado por uma turma de alunos. (TARDIF, 2007, p. 13).

Quando o profissional realiza seu trabalho com competência, domínio e responsabilidade, ele consegue se envolver no ambiente onde está inserido e mostrar que é peça importante para o trabalho que é desenvolvido nesse contexto. O hospital, tradicionalmente, é lugar de profissionais da área da saúde, mas, aos poucos, outras áreas vêm se destacando e ocupando esse espaço e, principalmente, contribuindo de forma significativa no processo educativo dos alunos-pacientes. $\mathrm{O}$ professor tem ganhado espaço e mostrado que sua presença tem feito muita diferença no hospital, sobretudo com relação à humanização. Esse novo olhar que vem sendo estabelecido está causando mudanças nas hierarquias rígidas, sem perder de vista a importância dos profissionais nem o fato de que, em alguns momentos, uns são mais necessários que outros, devido à necessidade apresentada pelo indivíduo hospitalizado. Todos os profissionais do hospital devem considerar que o paciente, apesar de hospitalizado, continua exercendo papéis sociais fora do hospital, ou seja, continua sendo aluno, filho, amigo, e, acima de tudo, continua sendo cidadão. Quando voltamos nosso olhar de forma mais profunda para o outro, respeitando-o, apesar de sua diversidade e singularidade; ao mesmo tempo, tratando-o como igual, ganhamos mais visibilidade e respeito.

\section{Considerações finais}

A educação tem um papel fundamental de mediadora das transformações sociais e pessoais. Essas transformações são constantes, levando-nos a repensar nossas ações e fazendo com que seja necessário o desenvolvimento 
contínuo de novas habilidades. Para tanto, fazse necessário que pensemos em novos espaços para o desenvolvimento do processo de ensino.

A importância da inserção da educação no ambiente hospitalar é notória. Diariamente, dezenas decrianças eadolescentessão internadas em hospitais para realizarem algum tratamento de saúde e, dessa forma, são afastados do convívio dos familiares e amigos. A continuidade dos estudos contribui significativamente para aliviar a tensão, a angústia e auxiliar no tratamento do enfermo. Com a classe hospitalar, a criança e o adolescente têm a possibilidade de manter o vínculo com o mundo externo, pois realizará algo que faz parte do seu dia a dia fora do hospital. Além disso, tem contribuído para tornar o ambiente hospitalar mais humano.

Possibilitar maior humanização no cuidado com a pessoa que vivencia sofrimento físico e mental é um compromisso ético, assim como garantir a continuidade aos estudos de crianças e jovens que são afastados de suas escolas para receberem tratamento de saúde. Acreditar na educação formal e informal no cotidiano dos indivíduos é uma contribuição para a diminuição das diferenças na qualidade de vida dos seres humanos.

Nesse sentido, a função do professor tem significativa importância, pois ele atua como mediador nos vários contextos onde ocorre o processo de ensino-aprendizagem. O professor da classe hospitalar é um vínculo necessário entre o hospital e a escola de origem do aluno e desempenha papel fundamental dentro da instituição de saúde e na vida desses alunos que estão vivenciando uma situação de medo e angústia dentro de um ambiente desconhecido.

O ambiente hospitalar é um dos espaços que tem recebido atenção para a inserção da educação; local em que educandos que se encontrem, ainda que temporariamente, afastados da escola para tratar de problemas de saúde possam ter o direito de dar continuidade aos seus estudos.
A peculiaridade da educação no ambiente hospitalar como sendo a de assegurar a manutenção dos vínculos escolares, de devolver a criança para a sua escola de origem com a certeza de que poderá reintegrarse ao currículo e aos colegas sem prejuízo pelo afastamento temporário ou, ainda, de demonstrar, na prática, que o lugar da criança é na escola, aprendendo e compondo experiências educacionais mediadas pelo mesmo professor que as demais crianças. (FONSECA, 2003, p. 8).

Estudos e pesquisas têm mostrado que a classe hospitalar é um serviço de extrema importância não só para a manutenção do processo de ensino-aprendizagem durante a hospitalização de crianças, adolescentes e jovens, mas também como auxiliar do tratamento a que os alunos-pacientes são submetidos. A significância desse trabalho ainda está pautada na área sociopolítica e na defesa da cidadania, sobretudo para possibilitar a reconquista da autoestima e da valorização do eu, que, muitas vezes, é perdida no processo de hospitalização.

Esse trabalho tem mostrado que o processo de ensino e aprendizagem não ocorre somente na escola, mas que a educação pode se efetivar até mesmo nos locais mais inusitados e inimagináveis.

A hospitalização pode causar um grande impacto na vida do sujeito, principalmente se ele for criança ou adolescente. Além da hospitalização, outros fatores relacionados ao tratamento e à doença são vivenciados com dor e sofrimento. A capacidade psíquica e intelectual também pode ser afetada, o que, inevitavelmente, reflete em suas funções de ensino e aprendizagem. Assim, o papel da educação no hospital vai além de trabalhar conteúdos formais e sistemáticos do currículo escolar, ela contribui para a adaptação do paciente à nova rotina e auxilia no desenvolvimento emocional e na recuperação psíquica do enfermo e de sua família. Para Fontes (2005, p. 13), a educação 
hospitalar propicia

o conhecimento e a compreensão daquele espaço, ressignificando não somente a ele, como à própria criança, sua doença e suas relações nessa nova situação de vida.
Pensar na expansão das classes hospitalares é uma necessidade emergente. Saúde e educação são direitos básicos, fundamentais e imprescindíveis para fortalecer a cidadania e garantir os direitos dos cidadãos.

\section{Referências}

BARBIER, R. A pesquisa-ação. Brasília: Liber Livro, 2007.

BRANDÃO, C. R. O que é educação. São Paulo: Brasiliense, 2007.

BRASIL. Estatuto da Criança e do Adolescente. 9. ed. São Paulo: Saraiva, 1999.

. Ministério da Educação e Cultura. Política Nacional de Educação Especial. Livro 1. Brasília: MEC/SEESP, 1994.

- Ministério da Educação. Classe hospitalar e atendimento pedagógico domiciliar: estratégias e orientações. Secretaria de Educação Especial, Brasília: MEC/SEESP, 2002.

FONSECA, E. S. da. A situação brasileira do atendimento pedagógico-educacional hospitalar. Revista Educação e Pesquisa, São Paulo, v. 25, n. 1, p. 117-129, jan./jun. 1999.

. Atendimento escolar no ambiente hospitalar. São Paulo: Memnon, 2003.

FONTES, R. A reinvenção da escola a partir de uma experiência instituinte em hospital. Revista Educação e Pesquisa, São Paulo, v. 30, n. 2, p.1-18, maio/ago. 2004.

. A escuta pedagógica à criança hospitalizada: discutindo o papel da educação no hospital. Revista Brasileira de Educação, Rio de Janeiro, n. 29, p. 119-139, maio/ago. 2005. 2009.

. Educação no hospital. Revista Presença Pedagógica, Belo Horizonte, v. 15, n. 90, nov./dez.

FREIRE, P. Pedagogia da autonomia: saberes necessários à prática educativa. Rio de Janeiro: Paz e Terra, 1998.

MATOS, E. L. M. O desafio ao professor universitário na formação do pedagogo para a atuação na educação hospitalar. 1998. 145f. Dissertação (Mestrado em Educação) - Pontifícia Universidade Católica, Paraná, 1998.

MUNHÓZ, M. A.; ORTIZ, L. C. M. Um estudo da aprendizagem e desenvolvimento de crianças em situação de internação hospitalar. Revista Educação: Pessoa, Saúde e Educação,Porto Alegre, v. 29, n. 58, p. 65-83, jan./abr. 2006.

ORTIZ, L. C. M.; FREITAS, S. N. Classe hospitalar: caminhos pedagógicos entre saúde e educação. Santa Maria: Editora da Universidade Federal de Santa Maria, 2005. 
PARANÁ. Secretaria de Estado da Educação. Superintendência de Educação. Diretoria de Políticas e Programas Educacionais. Serviço de Atendimento à Rede de Escolarização Hospitalar - SAREH. Curitiba: SEED, 2010. (Cadernos Temáticos).

PAULA, E. M. A T. de. Educação, diversidade e esperança: a práxis pedagógica no contexto da escola hospitalar. 2004. 300f. Tese (Doutorado em Educação) - Universidade Federal da Bahia, Salvador, 2004.

RITTMEYER L, S. R. P.; IMBROSIO L. O. Classe hospitalar Jesus: trajetória do jubileu de ouro (19502000). In: ENCONTRO NACIONAL DO ATENDIMENTO ESCOLAR HOSPITALAR, 1., 2000, Rio de Janeiro. Anais... Rio de Janeiro: Editora da Universidade Estadual do Rio de Janeiro, 2000, p. 19-21. Disponível: <http://www.escolahospitalar.uerj.br/anais.htm>. Acesso em: 21 ago. 2013.

TARDIF, M. Saberes docentes e formação profissional. Rio de Janeiro: Vozes, 2007.

VASCONCELOS, S. M. F. Clínica do discurso: a arte da escuta. Fortaleza: Premius, 2005.

Submetido em 23 de julho de 2014.

Aprovado em 11 de agosto de 2014. 